\title{
Estrutura intelectual dos estudos da competência informacional na perspectiva fenomenográfica: uma análise por meio da citação e cocitação
}

\author{
Ilídio Lobato Ernesto Manhique \\ Escola Superior de Jornalismo, Departamento de Biblioteconomia, Maputo, Moçambique \\ ilidiolobato@gmail.com \\ Helen de Castro Silva Casarin \\ Universidade Estadual Paulista, Faculdade de Filosofia e Ciência, Departamento de Ciência da \\ Informação, Marília, SP, Brasil \\ helenc@marilia.unesp.br
}

DOI: https://doi.org/10.26512/rici.v11.n3.2018.10460

Recebido/Recibido/Received: 2018-05-23

Aceitado/Aceptado/Accepted: 2018-06-08

Resumo: As análises de citação e cocitação são indicadores bibliométricos que fornecem dados objetivos para a compreensão da estrutura intelectual de um domínio do conhecimento. Esta pesquisa teve como objetivo caracterizar, a partir da análise de citações e cocitações, a estrutura intelectual dos estudos da competência informacional com enfoque na abordagem fenomenográfica ou relacional. Especificamente, mapeou-se os autores mais produtivos, autores mais citados, sua filiação institucional, países que mais produzem sobre a temática e criou-se, por meio do software Ucinet, a rede de cocitação indicando a frequência de cocitação entre os autores. A coleta de dados foi feita por meio de um levantamento na base de dados internacional - SCOPUS, - utilizando a seguinte expressão de busca ("information literacy") AND ("phenomenographic" OR "relational*"). A pesquisa retornou apenas 18 trabalhos válidos, todos na língua inglesa, maioritariamente, produzidos por autores da Austrália, de onde provém o trabalho seminal sobre a abordagem fenomenográfica da competência informacional. Isto mostra que esta perspectiva teórico-metodológica ainda está em busca de sua penetração no campo da Ciência da Informação. Conclui-se que é necessário que sejam feitos estudos futuros, englobando outras bases de dados internacionais para se ter o contexto global sobre a estrutura intelectual deste objeto.

Palavras-chaves: Competência em informação. Citações. Cocitações. Fenomenografia. Redes.

\section{Intellectual structure of Phenomenographics studies of information literacy: citation and co-citation} analysis

Abstract: The citation and co-citation analyze are indicators that provide objective data to understand the intellectual structure of knowledge domain. Its potentialities have global recognition to assess Science and Technology of several countries. This research aimed to characterize, through citation and co-citation, the intellectual structure of information literacy studies based in phenomenographic or relational approach. Specifically, it aimed to map the most productive and cited authors, their institutional filiation and countries that publish more about this subject, and through Ucinet software was created the co-citation network. The collecting data was carried out in an international database SCOPUS, using the following search expression: ("information literacy") AND ("phenomenographic" OR "relationa/*"). The research resulted in 18 valid articles, all published in English, especially by Australian researchers, where were produced the seminal works about phenomenographic approach of information literacy. This shows that this theoretical and methodological approach still looking for 
international penetration. It concludes that is necessary to carry out future studies that include other international databases to understand the global context about this subject.

Key words: Information literacy. Citation. Co-citation. Network. Phenomenography.

\section{La estructura intelectual de los estudios da la alfabetización informacional en la perspectiva fenomenográfica: un análisis a partir de la citación y co-citación}

Resumen: Los análisis de citación y co-citación son indicadores bibliométricos que facilitan obtener datos objetivos ara la comprensión de la estructura intelectual de un dominio de conocimiento. Esta investigación tiene como objetivo caracterizar, a partir del análisis de citaciones y cocitaciones, la estructura intelectual de los estudios de la alfabetización informacional con enfoque en el abordaje fenomenológico, o relacional. Espcificamente, se mapearon los autores más productivos, autores más citados, su afiliación institucional, países que más producen sobre la temática y se creó, por medio del software Ucinet, la red de cocitación indicando la frecuencia de cocitación entre los autores. La búsqueda de bibliográfica fue realizada por medio de un levantamiento en la base de datos internacional -SCOPUS- utilizando la siguiente expresión de búsqueda ("information literacy") AND ("phenomenographic" OR "relational*"). La investigación devolvió 18 estudios válidos, todos en idioma inglés, mayoritariamente, producidos por autores de Australia, de donde provienen los trabajos seminales sobre el abordaje fenomenográfico de la alfabetización informacional. Esto muestra que esta perspectiva teórico-metodológica aún está en la búsqueda de su inserción en el campo de la Ciencia de la Información. Se concluye que se realicen futuras investigaciones, englobando otras bases de datos informacionales para obtener un contexto global sobre la estructura intelectual de este objeto de estudio.

Palabras-clave: Alfabetización informacional. Citación. Co-citación. Fenomenografía. Red.

\section{Introdução}

Por meio da análise de citação e cocitação, esta pesquisa visa caracterizar a estrutura intelectual dos estudos de competência informacional que enfocam a abordagem fenomenógráfica ou relacional, que é uma perspectiva teórico-metodológica introduzida por Christine Bruce (1997) na Ciência da Informação. Esta pesquisa assume a perspectiva de domínio, porque pretende estudar uma área do conhecimento, dentro da qual um grupo de profissionais se encontra estruturado como comunidade discursiva, por estarem articulados por vários elementos identitários, tais como linguagem e pensamento (HJORLAND; ALBRECHTSEN; 1995; GUIMARÃES, 2014).

Um domínio pode ser entendido de diversas formas, entre as quais, como um campo nas suas diferentes especialidades, um conjunto de literatura sobre um determinado objeto, e compreende o estudo de uma comunidade discursiva e o papel desempenhado por estes pesquisadores na ciência. Como ferramenta metodológica, é uma importante abordagem para a caracterização e avaliação da ciência, pois permite identificar e analisar as condições sob as quais o conhecimento científico é construído e socializado. (HJORLAND; ALBRECHTSEN, 1995; GRÁCIO; OLIVEIRA, 2013).

No campo da Ciência da informação, destacam-se as onze abordagens propostas por Hjorland (2002), as quais abarcam os estudos bibliométricos, particularizando as análises de citação e cocitação, porque fornecem um diagnóstico mais objetivo para a caracterização de 
um domínio. Devido a algumas inconsistências que caracterizam este método, o autor recomenda que seja combinado com outras abordagens, tais como, estudos epistemológicos, estudos históricos e outros estudos com foco qualitativo que caracteriza as Ciências Sociais.

Como domínio de conhecimento, a competência informacional assume, desde as últimas três décadas, uma das posições de destaque nas pesquisas da Ciência da Informação. Desde que Zurkowisky utilizou a expressão information literacy (1974), a mesma ganhou interesse global no universo biblioteconômico e da Ciência da Informação, buscando ressignificar a função educacional que, tradicionalmente, as bibliotecas desenvolvem.

Foi em torno deste foco que Bruce (1997) propôs uma nova abordagem da competência informacional, que a designou de relacional ou fenomenográfica, que se fundamenta nos princípios da epistemologia construtivista e interpretativista. Esta perspectiva constitui a ruptura com a visão já consolidada e hegemônica na Ciência da Informação, que estuda a competência informacional em torno da aplicação de modelos e padrões que, na maioria das vezes, são desprovidos dos aspectos contextuais que caracterizam todas ações que visam fomentar a aprendizagem.

Por ser uma tendência emergente de pesquisa, este trabalho investiga, por meio da análise de citação e cocitação, como o domínio de estudos da competência informacional com enfoque fenomenográfico se encontra estruturado, analisando a literatura produzida neste campo.

Do ponto de vista específico, busca-se conhecer os autores mais produtivos nesta temática, os autores mais citados, sua filiação institucional os países que mais produzem pesquisas de competência informacional enfocadas na abordagem fenomenográfica ou relacional. Analisar as citações e a cocitação permite-nos compreender as frentes de pesquisa de um campo, assim, como determinar os teóricos e/ou autores pioneiros sobre uma determinada temática.

\section{Fenomenografia e competência informacional}

A fenomenografia é uma abordagem teórico-metodológica que surgiu, na década de 1970, a partir dos estudos empíricos sobre a aprendizagem conduzidos pelo Departamento de Educação da Universidade de Gotenburgo, na Suécia. Tem como autores pioneiros Marton, Saljo e Booth, e se preocupa com a variação da experiência da aprendizagem dos indivíduos.

De acordo com Marton (1986), a fenomenografia é um método de pesquisa qualitativa que visa mapear as diferentes formas pelas quais as pessoas experienciam, conceituam, percebem e compreendem os vários aspectos de um fenômeno dentro de um determinado contexto. Ela não se preocupa apenas com o fenômeno experienciado ou vivenciado, nem com 
as pessoas que o vivenciam, mas com as relações existentes entre os seres humanos e o mundo que os rodeia.

Considerando que a experiência varia de acordo com as pessoas e com contexto, a fenomenografia não tem como intuito encontrar leis gerais de pensamento aplicáveis em quaisquer situações. Pelo contrário, no âmbito fenomenográfico, o pensamento é descrito em termos do que é percebido e a pesquisa nunca é separada do conteúdo do pensamento. 0 objetivo consiste em explorar todos os entendimentos que as pessoas têm sobre um fenômeno e ordená-los em categorias conceituais (MARTON, 1986; ANDRETTA, 2012).

A sua epistemologia é baseada no construtivismo, que enfatiza a importância de compreender a perspectiva do aprendente. Nesta abordagem, a aprendizagem é vista como uma atividade de construção de significados e não como transferência do conhecimento de um especialista para o estudante. (LIMBERG, SUNDIN; TALA, 2012).

Esta metodologia procura, a partir das concepções dos indivíduos, construir categorias de descrição ou analíticas, que reflectem o número de formas qualitativamente diferentes em que um fenômeno pode ser descrito e compreendido. Esta abordagem desenvolveu-se como alternativa à tradição positivista, behaviorista e à prevalência de pesquisas quantitativas. A posição epistemológica da fenomenografia baseia-se no princípio da intencionalidade, que inclui uma visão não-dualista entre o indivíduo e o meio onde a experiência se desenrola. (SVENSSON, 1997)

Apesar de operar no âmbito da experiência, a fenomenografia difere-se da fenomenologia em vários aspectos. Enquanto a fenomenologia procura a essência, com o intuito de encontrar um resultado comum intersubjetivo de um fenómeno, a fenomenografia assume que os fenómenos são vivenciados de formas qualitativamente diferentes, ou seja, procura a variação da experiência. A fenomenologia está orientada para o método e para e experiência individual e a fenomenografia para o conteúdo e para o significado da experiência coletiva (BERNARD et al., 1999).

Outro aspecto distintivo e característico da fenomonografia é a adoção de uma perspectiva de "segunda ordem". Por meio desta perspectiva, o pesquisador é orientado a descrever as formas como as pessoas concebem, percebem e experienciam os vários aspectos do mundo à sua volta. (YATES, PARTRIDGE, BRUCE, 2012). Por isso, os fenômenos são investigados a partir da experiência dos participantes, em vez da experiência do pesquisador. Sendo a fenomenografia uma abordagem de "segunda ordem", não procura descrever o fenómeno como ele é, o que seria uma abordagem de primeira ordem, descreve-o como ele é concebido pelos indivíduos (MARTON, 1981; 1986). 
Quando se reflecte sobre a competência informacional, é necessário observá-la em sua natureza complexa e holística, abrangendo a sua multiplicidade de abordagens, e procedendo desta forma, o conceito de competência informacional irá variar conforme as opções teóricas dos pesquisadores.

Na literatura da Ciência da Informação, a competência informacional tem sido definida como a habilidade de buscar, selecionar, avaliar criticamente e o uso da informação para a resolução de problemas em vários contextos. Limberg, Sundin e Talja (2012) interpretam a ênfase na busca e seleção da informação dos vários programas de competência informacional como indicativa da longa tradição da educação de usuários das bibliotecas, inicialmente, focada nas fontes, técnicas de busca e avaliação da informação. Esta concepção enraizada nas bibliotecas está voltada ao "ensino" da competência informacional.

Adotando a abordagem fenomenográfica, a competência informacional constitui uma forma de aprendizagem a partir da experiência dos indivíduos com a informação e tecnologias de informação. Esta concepção foi introduzida na Ciência da Informação, em 1997, por Christine Bruce, em sua tese de doutorado que gerou um modelo relacional designado "The seven faces of information literacy".

O interesse da fenomenografia em explorar os padrões de variações das formas de experimentar o fenômeno difere dos esforços de descrever a competência informacional como um conjunto genérico de habilidades aplicável em qualquer situação independentemente do contexto. Enquanto a definição clássica de competência informacional da American Library Association (1989) está ligada à habilidade de localizar, avaliar e usar efetivamente a informação, adotando a abordagem relacional, "[...] a competência informacional é vista como a base para a aprendizagem que é experimentada pelos estudantes [...]" (ANDRETTA, 2012, p. 3 , tradução nossa).

O processo fenomenográfico de experienciar um fenômeno é baseado na estrutura de consciência (structure awareness) e consiste em duas dimensões. A primeira é o aspecto referencial ou o "O Quê" da experiência, que fornece diferentes conceitualizações do fenômeno. A segunda dimensão, conhecida como estrutural, ou seja, o "Como" da experiência, que fornece as diferentes práticas do fenômeno (ANDRETTA, 2012).

Em outras palavras, a fenomenografia investiga o alcance dos significados acerca de um fenômeno dentro de um grupo como um grupo, mais do que focalizar o alcance dos significados individuais dentro de um grupo. Estes elementos sígnicos são traduzidos em categorias que descrevem as experiências coletivas do fenômeno, e a variação entre as experiências é gerada por uma visão composta pelas dimensões estrutural e referencial. 
As categorias de descrição são relacionadas umas das outras por meio de uma matriz hierárquica que mostra uma progressão das mais simples até as mais complexas formas de experienciar um fenômeno.

\section{Estudos métricos da Ciência da Informação}

Os estudos métricos da informação são parte integrante do escopo de investigação da Ciência da Informação, e constituem uma das onze abordagens de análise de domínio propostas por Hjorland (2002). Através de indicadores quantitativos, estas pesquisas tornaram-se imprescindíveis para avaliar os resultados da produção científica, assim como para a criação e revisão de políticas de ciência e tecnologia.

A aplicação das tecnologias de informação trouxe novos suportes e formatos de informação, contribuindo para o alargamento do horizonte conceitual e pragmático dos estudos métricos. Estas circunstâncias foram responsáveis pela proliferação de novos conceitos ligados aos estudos métricos da informação, cuja aplicação na produção, organização e disseminação da informação depende do universo de objetos que se estudam. 0 termo bibliometria, por exemplo, devido ao seu radical (Biblio), sugere relações semânticas com o suporte livro e, por associação, ao termo biblioteca. Por sua vez, termos como informetria, cientometria, webometria, representam práticas de mensuração da informação em modalidades convencionais ou na Web (BUFREN, 2005).

Estes estudos abarcam um conjunto de indicadores que podem ser agrupados três, nomeadamente: indicadores de produção, indicadores de citação e indicadores de ligação. Estes parâmetros contribuem para a visualização a produção científica dos pesquisadores, dos temas, das instituições, das áreas do conhecimento, dos países com maior produtividade, da frente de pesquisa de um campo do conhecimento, das redes de colaboração entre cientistas, grupos, instituições ou países e redes de citação e cocitação (GRÁCIO; OLIVEIRA, 2011; 2013).

Apesar das potencialidades destes indicadores, Spinak (1998) sustenta que as atividades científicas devem ser avaliadas tendo em conta o contexto conceptual, histórico, cultural e social em que elas se encontram inseridas. Quer dizer, a ciência e tecnologia não podem ser avaliadas por meio de indicadores absolutos, mas pela expectativa da sociedade que ela serve. Uma das formas de relativização destes indicadores é a sua combinação com outros métodos qualitativos que alicerçam as Ciências Sociais.

Macias-Chapula (1998) aponta algumas limitações destes indicadores, entre as quais a fraca cobertura de bases de dados, na medida em que elas não são representativas em relação a todo o tipo de informação produzida. Como exemplo, a autora aponta o fato dessas bases de dados não incluírem os livros, os capítulos de livros e as teses, bem como a chamada literatura 
cinzenta (relatórios técnicos, conferências, notas técnicas). Ademais, a principais bases de dados internacionais, tais como a Web Of Science e a SCOPUS, estão ligadas aos países que configuram a ciência mainstream, contribuindo para obscurecer e "periferizar" a produção científica dos países fora dessa corrente.

Spinak (1998) explica que os indicadores cienciométricos, grande parte dos quais, derivados do Science Citation Index e outras bases de dados, se manifestam a favor dos países desenvolvidos em detrimento das publicações dos países do Terceiro Mundo. É que essas ferramentas foram concebidas e são eficazes para a avaliar a C\&T dos países desenvolvidos, no entanto apresentam graves problemas epistemológicos para a avaliar a dos países menos desenvolvidos. Por exemplo, uma das maiores ferramentas de análises bibliométricas provém do aporte fornecido pelas bases de dados da Information Scientific Institute (ISI), cujos critérios de seleção são parciais e desajustados com a realidade da C\&T dos países menos desenvolvidos.

\section{Análises de citação e cocitação}

O campo científico desempenha funções múltiplas, dentre as quais, as de produção e socialização do conhecimento para que seja apropriado, questionado, utilizado ou reutilizado pelos demais membros da sociedade. Mas também, tem a função de atribuir o reconhecimento para aqueles contribuem com a criação de novas ideias em diferentes campos do conhecimento (MACIAS-CHAPULA, 1998; GRÁCIO; OLIVEIRA, 2013). Uma das formas mais conhecidas de recompensa tem sido por meio da citação, que é entendida como a relação entre dois documentos, isto é, aquele que cita (citante) e aquele que é citado.

Macias-Chapula (1998) reconhece que citação é um dos elementos fundamentais para determinar a relevância do conhecimento produzido pelos autores, mas explica que é necessário considerar os vários fatores que influenciam a escolha de documentos ou autores para citar, destacando os aspectos psicológicos e sociais, a língua de publicação, a extensão do artigo, o conhecimento do autor, o formato do documento.

Small (2004) faz menção ao que Merton designa de "Efeito Mateus, que contribui para a desigualdade de citações entre os autores mais consagrados e os menos conhecidos, uma vez que os documentos mais citados tendem a ser constante e continuamente citados. Outro critério de citação é o Efeito "Halo", em que citação é influenciada pela autoridade do autor, pelo prestígio da revista ou das instituições em que os autores se encontram vinculados. Tanto no primeiro, quanto no segundo, ambos os critérios de citação aumentam a estrutura de classes no campo científico. 
O estudo de citações e cocitações constituem procedimentos fundamentais na análise da interlocução entre os pesquisadores e o seu contributo nas diferentes áreas do conhecimento, e são ferramentas essenciais para a compreensão da estrutura intelectual e do processo comunicativo de um domínio.

A análise de citação de autores pode ser definida como a investigação de um grupo de atores ou pesquisadores estruturalmente organizados em uma rede social e cognitiva de uma comunidade científica particular. Ela identifica os pesquisadores com grande impacto numa determinada área e dá visibilidade para o referencial teórico que os suporta, assim como seus conceitos, objetos, métodos, contribuindo para o entendimento de uma comunidade científica. Por outro lado, permite a identificação de grupos de cientistas e suas publicações, assim como a "vanguarda" de pesquisadores que constroem um novo conhecimento na área, e assim apontando novos paradigmas e procedimentos metodológicos relevantes para a área e para o domínio (GRÁCIO; OLIVEIRA, 2013; GLANZEL, 2003).

Segundo Small (1974), a análise de cocitação deriva da análise de citação, e examina a frequência com que dois autores ou documentos são, concomitantemente, citados na produção científica de uma área. Como premissa básica, a análise de cocitação indica que quando dois ou mais documentos, autores, revistas ou outras entidades são simultaneamente citados em um terceiro documento posterior, então existe, pelo menos, na perspectiva do autor citante, uma similaridade de assunto. (MIGUEL; HERRERO-SOLANA, 2008). Por outro lado, quando ocorre maior frequência de cocitação entre documentos sugere que existe maior proximidade entre os autores cocitados. (SMALL, 1974; MIGUEL; HERRERO-SOLANA, 2008).

Estes estudos são baseados na frequência em que os autores ou documentos são citados simultaneamente na produção científica de um campo e mostram como a estrutura do conhecimento de uma área é percebida pelos autores. (SMALL, 1974; GRÁCIO; OLIVEIRA, 2013).

Esta técnica, que foi utilizada, pela primeira vez, por Small ${ }^{1}$ e Marshakova ${ }^{2}$ para a análise de cocitação de documentos e por White e Griffith $^{3}$ para a cocitação de autores, tem sido usada em vários trabalhos com o objetivo de revelar vários aspectos ligados à estrutura intelectual e composição de um campo científico, identificação de especialidades, frentes de

\footnotetext{
${ }^{1}$ SMALL, H. Cocitation in the scientific literature: a new measure of the relationship between two documents, Journal of the American Society for Information Science, v. 24, n. 4, p. 265-269, 1973.

2 MARShakova, I. V. System of document connection based on references, Nauchno-Teknichescaya Informatisya, Series II, v. 6, p. 3-8, 1973.

${ }^{3}$ WHITE, Howard D.; GRIFFITH, Belver C. Author cocitation: A literature measure of intellectual structure. Journal of American Society for Information Science. V. 32, n. 3, p. 163-171, July 1981.
} 
pesquisa, assim como as mudanças da estrutura intelectual ao longo do tempo. (MIGUEL; HERRERO-SOLANA, 2008).

No âmbito da sua aplicação, a análise de cocitação apresenta efeitos paradigmáticos, porque, naturalmente, os seus padrões não são estáticos ou permanentes, pois eles podem mudar ao longo do tempo, devido às transfigurações que ocorrem dentro da estrutura intelectual de um campo. Conforme Small (1974), visto que a cocitação refere-se à relação que é estabelecida pelos autores citantes, então, quando mensuramos a intensidade da cocitação, estamos mensurando o grau de relacionamento ou associação entre os documentos assim como são é percebido pelos autores citantes. Devido à dependência em relação aos autores citantes, os modelos podem mudar ao longo do tempo devido às, inevitáveis, mudanças que ocorrerem dentro de um campo. Quer dizer, os padrões de cocitação mudam assim que mudam os interesses e modelos intelectuais de um domínio.

\section{Procedimentos metodológicos}

Esta pesquisa é de caráter exploratório e teve como objetivo compreender as manifestações do domínio dos estudos da competência informacional, tendo em conta a abordagem fenomenográfica, que prioriza as variações com que as pessoas percebem e experienciam um fenômeno. Ou seja, é uma perspectiva que visa mapear as concepções dos indivíduos sobre um determinado fenômeno, que no caso é a competência informacional.

A efetivação desta pesquisa ocorreu em três etapas, sendo que a primeira consistiu no levantamento da produção científica brasileira relativa à competência informacional com enfoque na abordagem fenomenográfica ou relacional. Nesta etapa da pesquisa, as buscas foram feitas na $\mathrm{BRAPCl}$, que é uma base de dados que agrega 57 periódicos da área da Ciência da Informação, daí que considerarmos representativa para compreender os processos de produção científica da área no contexto brasileiro.

As buscas foram efetuadas entre Agosto e Dezembro de 2017, utilizando as expressões "competência informacional" AND "fenomenografia", "competência informacional" AND "abordagem relacional", "Competência em informação" AND "abordagem fenomenográfica", "competência em informação" AND "abordagem relacional". Estas buscas retornaram "zero" resultados, o que evidencia que este enfoque teórico, conceitual e metodológico da competência informacional ainda não está sendo explorado na Ciência da Informação brasileira.

Esta constatação levou-nos a buscar dados sobre este domínio do conhecimento nas bases de dados internacionais. No mesmo período, as buscas foram feitas na SCOPUS, por ser uma das bases de dados onde estão indexados vários periódicos de referência da área da 
Ciência da Informação. Assim, foi possível visualizar como estas pesquisas têm sido desenvolvidas no contexto dos países que configuram a ciência mainstream e a sua contribuição para os estudos mais holísticos da competência informacional.

O marco temporal das buscas foi o ano de 1997, visto que foi neste período em que Christine Bruce introduziu a abordagem relacional ou fenomenográfica da competência informacional no campo da Ciência da Informação. Utilizando as ferramentas de busca disponibilizadas por esta base de dados, que permitem a filtragem e maior precisão nos resultados recuperados, foi feita a consulta, apenas em inglês, utilizando a expressão ("information literacy") AND ("phenomenographic" OR "relational*"), buscando tais termos no título, no resumo e nas palavras-chaves.

A consulta recuperou 26 artigos, mas para confirmar se os textos recuperados versavam, efetivamente, sobre o assunto tratado nesta pesquisa, fez-se a análise de conteúdo do texto completo nos artigos que ofereciam algumas dúvidas quanto à temática abordada. Este mecanismo de filtragem resultou na seleção final de 18 artigos e desdobrada a coautoria resultou 21 autores.

A terceira etapa consistiu na aplicação dos procedimentos bibliométricos, visando construir a matriz de ocorrência de citação. Nesta etapa, foram contabilizadas todas as referências dos artigos selecionados, sendo também desdobrados os artigos de coautoria, de modo que todos os autores fossem contemplados na matriz de ocorrência de citação. Este procedimento resultou em um total de 747 referências e 464 autores citados.

Dada a quantidade de autores, para a elaboração da matriz de cocitação foram considerados aqueles que tivessem sido citados, pelo menos, 5 vezes, o que resultou em 28 autores, que foram colocados em uma matriz de ocorrência no Excel 28/28, com suporte da função matemática "SOMARPRODUTO" (Tabela 1). 
Tabela 1: Matriz de cocitação dos estudos da competência informacional na perspectiva fenomenográfica

\begin{tabular}{|c|c|c|c|c|c|c|c|c|c|c|c|c|c|c|c|c|c|c|c|c|c|c|c|c|c|c|c|c|}
\hline & 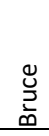 & 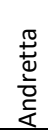 & $\begin{array}{l}\frac{n}{0} \\
\frac{0}{0} \\
\frac{3}{3} \\
w \\
\end{array}$ & $\begin{array}{l}\frac{c}{0} \\
\stackrel{0}{\frac{1}{\pi}} \\
\stackrel{\pi}{\Sigma}\end{array}$ & 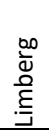 & 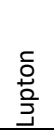 & 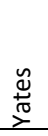 & 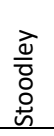 & 응 & 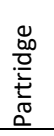 & $\begin{array}{l}\text { Fे } \\
\stackrel{0}{\circ} \\
\end{array}$ & 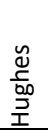 & 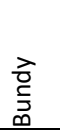 & 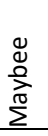 & 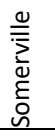 & 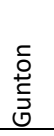 & 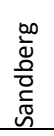 & $\begin{array}{l}\bar{\varpi} \\
\stackrel{0}{0} \\
0 \\
\end{array}$ & 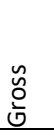 & $\frac{. \bar{\varrho}}{3}$ & 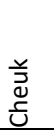 & 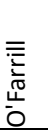 & 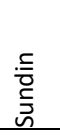 & $\begin{array}{l}\text { 응 } \\
\text { 으 }\end{array}$ & 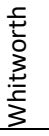 & ઠ & $\begin{array}{l}\overrightarrow{0} \\
\frac{c}{\pi} \\
\underline{0} \\
\end{array}$ & 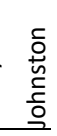 \\
\hline Bruce & 14 & 4 & 9 & 10 & $\begin{array}{l}1 \\
2\end{array}$ & 9 & 7 & 5 & 6 & 9 & 9 & 6 & 6 & 5 & 5 & 5 & 5 & 4 & 1 & 1 & 4 & 3 & 2 & 3 & 3 & 2 & 4 & 2 \\
\hline Andretta & & 4 & 4 & 4 & 4 & 4 & 3 & 2 & 2 & 4 & 4 & 2 & 3 & 2 & 3 & 1 & 0 & 1 & 0 & 0 & 2 & 2 & 2 & 0 & 2 & 1 & 3 & 1 \\
\hline Edwards & & & 9 & 9 & 9 & 8 & 6 & 5 & 5 & 8 & 8 & 4 & 4 & 5 & 5 & 5 & 4 & 4 & 0 & 0 & 3 & 3 & 2 & 2 & 3 & 1 & 3 & 1 \\
\hline Marton & & & & 10 & $\begin{array}{l}1 \\
0\end{array}$ & 8 & 7 & 5 & 6 & 9 & 9 & 5 & 4 & 5 & 5 & 5 & 4 & 4 & 0 & 0 & 3 & 3 & 2 & 2 & 3 & 1 & 3 & 1 \\
\hline Limberg & & & & & $\begin{array}{l}1 \\
2\end{array}$ & 9 & 7 & 5 & 6 & 9 & 9 & 5 & 5 & 5 & 5 & 5 & 4 & 4 & 0 & 1 & 4 & 3 & 2 & 3 & 3 & 2 & 3 & 2 \\
\hline Lupton & & & & & & 9 & 6 & 5 & 5 & 8 & 8 & 3 & 4 & 5 & 5 & 5 & 4 & 4 & 0 & 1 & 3 & 3 & 2 & 2 & 3 & 2 & 3 & 1 \\
\hline Yates & & & & & & & 7 & 5 & 6 & 7 & 7 & 2 & 2 & 4 & 4 & 4 & 3 & 4 & 0 & 0 & 3 & 3 & 1 & 2 & 2 & 1 & 2 & 1 \\
\hline Stoodley & & & & & & & & 5 & 5 & 5 & 5 & 1 & 2 & 4 & 3 & 4 & 3 & 4 & 0 & 0 & 2 & 3 & 1 & 2 & 2 & 0 & 2 & 0 \\
\hline Lloyd A & & & & & & & & & 6 & 6 & 6 & 2 & 2 & 4 & 3 & 4 & 3 & 4 & 0 & 0 & 2 & 3 & 1 & 2 & 2 & 0 & 2 & 0 \\
\hline Partridge & & & & & & & & & & 9 & 9 & 4 & 4 & 5 & 5 & 5 & 4 & 4 & 0 & 0 & 3 & 3 & 2 & 2 & 3 & 1 & 3 & 1 \\
\hline Booth & & & & & & & & & & & 9 & 4 & 4 & 5 & 5 & 5 & 4 & 4 & 0 & 0 & 3 & 3 & 2 & 2 & 3 & 1 & $B$ & 1 \\
\hline Hughes & & & & & & & & & & & & 6 & 3 & 2 & 2 & 1 & 1 & 0 & 0 & 0 & 0 & 1 & 1 & 0 & 2 & 0 & 2 & 0 \\
\hline Bundy & & & & & & & & & & & & & 6 & 3 & 3 & 2 & 2 & 1 & 0 & 0 & 2 & 2 & 2 & 1 & 3 & 0 & 3 & 1 \\
\hline Maybee & & & & & & & & & & & & & & 5 & 4 & 4 & 3 & 3 & 0 & 0 & 2 & 3 & 1 & 1 & 3 & 0 & 2 & 0 \\
\hline Somerville & & & & & & & & & & & & & & & 5 & 3 & 2 & 2 & 0 & 0 & 3 & 3 & 1 & 0 & 3 & 1 & 2 & 1 \\
\hline Gunton & & & & & & & & & & & & & & & & 5 & 4 & 4 & 0 & 0 & 2 & 2 & 1 & 2 & 2 & 0 & 1 & 0 \\
\hline Sandberg & & & & & & & & & & & & & & & & & 5 & 3 & 0 & 0 & 1 & 1 & 0 & 2 & 1 & 0 & 0 & 0 \\
\hline Cooper & & & & & & & & & & & & & & & & & & 4 & 0 & 0 & 2 & 2 & 1 & 2 & 1 & 0 & 1 & 0 \\
\hline Gross & & & & & & & & & & & & & & & & & & & 1 & 0 & 0 & 0 & 0 & 0 & 0 & 0 & 0 & 0 \\
\hline Julien & & & & & & & & & & & & & & & & & & & & 1 & 0 & 0 & 0 & 0 & 0 & 1 & 0 & 0 \\
\hline Cheuk & & & & & & & & & & & & & & & & & & & & & 4 & 2 & 1 & 1 & 1 & 1 & 1 & 2 \\
\hline O'Farrill & & & & & & & & & & & & & & & & & & & & & & 3 & 1 & 0 & 2 & 0 & 2 & 0 \\
\hline Sundin & & & & & & & & & & & & & & & & & & & & & & & 2 & 0 & 1 & 0 & 2 & 0 \\
\hline Todd R. & & & & & & & & & & & & & & & & & & & & & & & & 3 & 0 & 0 & 0 & 1 \\
\hline Whitworth & & & & & & & & & & & & & & & & & & & & & & & & & 3 & 0 & 2 & 0 \\
\hline Boon & & & & & & & & & & & & & & & & & & & & & & & & & & 2 & 0 & 1 \\
\hline Candy & & & & & & & & & & & & & & & & & & & & & & & & & & & 4 & 0 \\
\hline Johnston & & & & & & & & & & & & & & & & & & & & & & & & & & & & 2 \\
\hline
\end{tabular}

Fonte: Elaboração própria

Os resultados de cocitação são apresentados na figura 1 e com recurso ao software Ucinet, criou-se a rede de cocitação entre os autores, que permite visualizar a frequência e a densidade de cocitação na rede.

\section{Resultados}

As buscas realizadas recuperaram apenas 26 títulos que enfocam a competência informacional com base na abordagem fenomenográfica ou relacional, dos quais 8 foram negativos. Foram recuperados 18 trabalhos positivos (Apêndice 1), que desdobrando a coautoria incluem 21 autores, dos quais Christine Bruce é a autora que apresenta maior produção científica sobre a temática. 
A tabela 2 apresenta a lista dos autores com maior número de trabalhos publicados, sua origem e a sua filiação institucional. Na lista da produção científica, Bruce aparece com autoria individual em apenas 1 artigo, sendo coautora em outros 6 trabalhos. É importante destacar que, embora não haja uma regularidade na frequência de publicações, observa-se uma tendência de crescimento na quantidade de publicações voltadas a esta abordagem da competência informacional, visto que que 13 dos 18 artigos analisados foram publicados após o ano de 2012.

Tabela 2: Autores com maior produção científica

\begin{tabular}{l|l|l|l}
\hline Autores & $\begin{array}{l}\text { No } \\
\text { trabalhos }\end{array}$ & País & Filiação institucional \\
\hline Bruce C & 7 & Austrália & Queensland University of Technology \\
Partridge H & 5 & Austrália & Queensland University of Technology \\
Andretta S. & 3 & Reino Unido & London Metropolitan University \\
Estados & Duke University \\
Cooper H & 2 & Unidos & Austrália \\
Davis K & 2 & Austrália & Queensland University of Technology \\
Edwards S. L. & 2 & Austrália & Queensland University of Technology \\
Stoodley I. & 2 & Austrália & Queensland University of Technology \\
Hughes H & 2 & Austrália & Queensland University of Technology \\
Gunton L. & 2 &
\end{tabular}

Fonte: Elaboração própria

Nota-se que grande parte dos autores que publicam sobre a temática estão concentrados na Austrália e, maioritariamente, com a mesma filiação institucional, a Queensland University of Technology. Destaque para as pesquisas de Suse Andretta que tem contribuído para a inserção da abordagem fenomenográfica da competência informacional no contexto europeu, especificamente, no Reino Unido. Em relação à origem dos pesquisadores, a Austrália é pioneira nos estudos da competência informacional com enfoque fenomenográfico e conta com uma densa produção científica sobre a temática.

A concentração de pesquisas em poucos países revela o caráter recente destes estudos, tornando, assim, desafiantes as pesquisas futuras sobre este objeto para o seu aprofundamento teórico e metodológico. No caso do Brasil, quer na Base de Dados Referenciais de Artigos de Periódicos em Ciência da Informação (BRAPCI), quer na SCOPUS, não foi encontrado nenhum autor que pesquisa a competência informacional se baseando neste enfoque. Esse cenário revela, por outro lado, a interpretação ainda incompleta dos fundamentos teórico-metodológicos da competência informacional na Ciência da Informação brasileira.

A tabela 3 exibe a lista dos autores mais citados e o cumulativo de citações que cada um deles recebeu em toda a literatura analisada. Nota-se que os três autores mais citados são, simultaneamente, os que mais publicam sobre a temática, o que sugere que este domínio está em processo de construção e identificação da sua elite de pesquisa. 
Tabela 3: Autores mais citados

\begin{tabular}{l|l|l|l|l|l}
\hline Autores & No citações & Autores & No citações & Autores & No citações \\
\hline Bruce, C.S. & 125 & Partridge, H & 17 & Cooper, H. & 7 \\
Andretta, S. & 37 & Booth, S. & 15 & Gross, M. & 7 \\
Edwards, S. & 37 & Hughes, H. & 14 & Julien, H. & 7 \\
Marton, F & 31 & Bundy, A. & 12 & Cheuk & 6 \\
Limberg, L. & 23 & Maybee, C. & 11 & O'Farrill, R.T & 6 \\
Lupton, M. & 21 & Somerville, M & 11 & Sundin, O. & 6 \\
Yates, C.L. & 21 & Gunton, L. & 9 & Todd, R. & 6 \\
Stoodley, I. & 20 & Kirton, J. & 9 & Whitworth, A. & 6 \\
Lloyd A & 17 & Sandberg, J. & 8 & Boon, S. & 5 \\
& & & & Candy, P. & 5 \\
& & & & Johnston, B. & 5 \\
\hline
\end{tabular}

Fonte: Elaboração própria

Entre os autores mais citados, destaca-se Christine Bruce que recebeu um cumulativo de 125 citações, apresentando um desnível muito grande em relação aos restantes autores citados. Por exemplo, o segundo autor mais citado recebeu 37 citações.

A quantidade de citações aos trabalhos de Christine Bruce, pode estar associada ao fato dela ser a autora dos trabalhos seminais sobre a fenomenografia das competências informacionais e, por isso, ser referência obrigatória para os restantes investigadores que focalizam as suas pesquisas nesta abordagem.

Marton e Booth (31 citações e 15 citações, respectivamente) não são autores da Ciência da Informação, mas os seus trabalhos são citados de forma recorrente, porque foram os pioneiros na utilização o método fenomenográfico na área da Educação na Suécia, tendo sido importado para Ciência da Informação por Christine Bruce, quando publicou, em 1997, um dos seus trabalhos mais conhecidos, intitulado "The seven faces of information literacy".

Dos 464 autores citados em todos os trabalhados analisados, 219 receberam apenas uma citação, o que indicia a concentração de citações em um grupo restrito de autores já reconhecidos na área. 
Quadro 1: Principais canais de comunicação científica

\begin{tabular}{|l|l|l|l|}
\hline Canal de publicação & $\begin{array}{l}\text { No de } \\
\text { publicações }\end{array}$ & Páis & Tipo \\
\hline Aslib Proceedings: New Information Perspectives & 1 & & Anais \\
\hline College and Research Libraries & 1 & USA & Periódico \\
\hline $\begin{array}{l}\text { Communications in Computer and Information } \\
\text { Science }\end{array}$ & 2 & Germany & Periódico \\
\hline European Journal of Contemporary Education & 1 & Russia & Periódico \\
\hline Health Information and Libraries Journal & 1 & UK & Periódico \\
\hline International Information and Library Review & 1 & USA & Periódico \\
\hline Journal of Documentaion & 1 & UK & Periódico \\
\hline Library and Information Science Research & 4 & UK & Periódico \\
\hline $\begin{array}{l}\text { Library and Information Science Research in Asia- } \\
\text { Oceania: Theory and Practice }\end{array}$ & 2 & Australia & Periódico \\
\hline $\begin{array}{l}\text { Professional Development and Workplace Learning: } \\
\text { Concepts, Methodologies, Tools, and Applications }\end{array}$ & 2 & Capítulo de \\
\hline Reference services review & 2 & UK & Periódico \\
\hline
\end{tabular}

Fonte: Elaboração própria

Observa-se que neste domínio do conhecimento os autores privilegiam a publicação em periódicos científicos, mas também, em pequena escala, os anais de eventos e capítulos de livros. Embora os pesquisadores mais produtivos (Tabela 2) sejam oriundos da Austrália, os periódicos que mais veiculam publicações sobre a competência informacional na perspectiva fenomenográfica são dos Estados Unidos e Reino Unido, que são espaços que representam as pesquisas da Ciência mainstream, e publicados, apenas, na língua inglesa.

Portanto, devido a esta limitação, já apontada por Spinak (2003), faz-se necessário encontrar outros indicadores qualitativos que permitam compreender a completude deste domínio. Nesses termos, para o entendimento holístico do domínio da competência informacional, a análises bibliométricas devem ser combinadas com outras abordagens propostas por Hjorland (2002), com destaque para os estudos históricos e estudos epistemológicos, que abarquem um universo de bases de dados mais alargado.

Devido à invisibilidade dos traços que constituem a rede de cocitação, dos 28 autores constantes da matriz simétrica (Tabela 1), foram selecionados os primeiros 16 para a formar a rede de cocitação. As áreas dos retângulos se referem à frequência com que os autores são cocitados, e a espessura da reta à intensidade de citação pelos membros da comunidade científica. 
Figura 1. Rede de cocitação

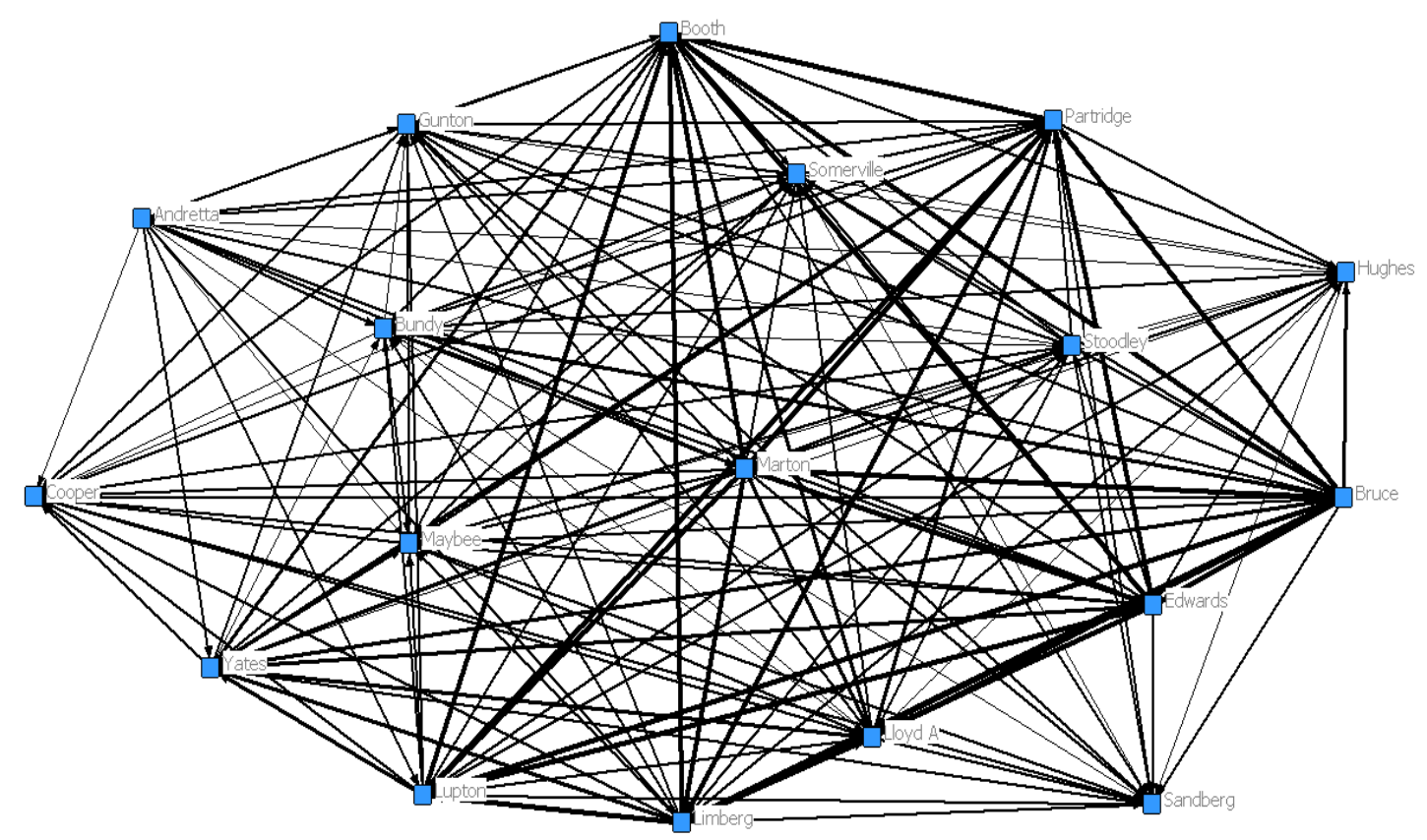

Fonte: Elaborado pelo autor

Observa-se que Bruce, Partridge e Limberg, para além da alta penetração na temática, dada pelo número de citações que receberam, são autores citados em maior números de trabalhos (68.75\% dos trabalhos). Entre os autores com maior frequência de cocitação destacam-se Bruce, Edwards e Lupton, apesar de outros tantos participarem de forma intensa na rede. Destaque para a Andretta que, apesar de ser uma das autoras mais citadas, apresenta pouca ocorrência de cocitação. A figura 1, mostra uma rede caracterizada por grande densidade e frequência de cocitação, o que significa que existe maior proximidade entre os autores que constituem a rede.

\section{Considerações finais}

Esta pesquisa teve como objetivo compreender, através da análise de citações e cocitações, como se encontra estruturado o domínio da competência informacional com enfoque fenomenográfico. A principal constatação reside na ausência de estudos sobre a temática no contexto da Ciência da Informação brasileira. No âmbito internacional, observouse a existência de poucos estudos com este enfoque teórico-metodológico da competência informacional, o que significa que é um viés que está em processo de inserção e consolidação na Ciência da Informação, visto que esta abordagem foi, recentemente, importada, nos finais da década de 1990, da área da educação. 
Este cenário pode ser observado pelo número reduzido de trabalhos recuperados em uma das maiores bases de dados de informação científica - a SCOPUS, bem como pelo número reduzido de autores com produção científica sobre esta temática.

Estas constatações mostram, por um lado, que os estudos da competência informacional têm vindo a deslocar a sua ênfase aos processos de aprendizagem dos indivíduos, nos qual a experiência e as concepções dos usuários sobre o fenômeno, desempenham um papel central. Com este foco, a competência informacional deixa de ser tratada como um conjunto de habilidades que se espera que sejam apropriadas pelos indivíduos, independentemente da situação e do contexto em que estão inseridos. Por outro, sugere-se a necessidade de integração deste enfoque teórico-metodológico na Ciência da Informação brasileira como forma de preencher a lacuna atualmente existente.

Vale ressaltar que os resultados desta pesquisa, apesar de generalizáveis dada à grandeza da base de dados utilizada para coleta de dados - a SCOPUS, podem apresentar algumas imperfeições, pois não visualizam como esta temática se encontra representada em outras bases de dados internacionais, tais como a Web of Science. Por isso, recomendam-se estudos futuros nesta e noutras bases de dados para se conhecer a extensão da produção científica neste domínio, os graus de associação entre os autores, assim como os autores que constituem a vanguarda de pesquisa neste domínio dos estudos da competência informacional.

\section{Referências}

ANDRETTA, Susie. Ways of Experiencing Information Literacy: Making the case for a relational approach. Oxford: Chandos, 2012. 220 p.

BRUCE, Christine S. Information literacy research and practice: An experiential perspective. In KURBANO` GLU, S.; GRASSIAN, E.; MIZRACHI, D.; CATTS, R.; AKÇA, S.; SPIRANEC, S. (Ed.) Worldwide Commonalities and Challenges in Information Literacy Research and Practice. Istanbul: Springer Turkey, 2013. p. 11-30. Disponível em https://link.springer.com/chapter/10.1007/978-3-319-03919-0 2 Acesso em: 25 Maio 2018.

BRUCE, Christine Susan. Las siete caras de la alfabetización en información en la enseñanza superior. Anales de Documentación, n. 6, p. 289-294, 2003. Disponível em http://revistas.um.es/analesdoc/article/view/3761/3661 Acesso em: 30 ago. 2017.

BUFREM, L., PRATES, Y. O saber científico registrado e as práticas da mensuração da informação. Ciência da Informação, Brasília, v.34, n. 2, p. 9-25, 2005. Disponível em http://revista.ibict.br/ciinf/article/view/1086 Acesso em: 5 Nov. 2017.

GLÄNZEL, W. Bibliometrics as a research field: a course on theory and application of bibliometric indicators. Course Handouts, 2003. Disponível em 
http://vunus.hacettepe.edu.tr/ tonta/courses/spring2011/bby7a04/bibliometrics-as-aresearch-field-Bib Module KUL.pdf Acesso em: 24 Maio 2018.

GUIMARÃES, J. A. C.; TOGNOLI, N. B. Provenance as a Domain Analysis Approach in Archival Knowledge Organization. Knowledge Organization, v. 42, n. 8, p. 562-569, 2015.

HJØRLAND, B. Domain analysis in information science: eleven approaches-traditional as well as innovative. Journal of Documentation, v. 58, n. 4, p. 422-462, 2002. Disponível em https://www.emeraldinsight.com/doi/abs/10.1108/00220410210431136 Acesso em: 30 Set. 2017.

HJØRLAND, B.; ALBRECHTSEN, H. Toward a new horizon in Information Science: domainanalysis. Journal of the American Society for Information Science, v. 6, n. 6, p. 400-425, 1995. Disponível em https://onlinelibrary.wiley.com/doi/abs/10.1002/\%28SICl\%2910974571\%28199507\%2946\%3A6\%3C400\%3A\%3AAID-ASI2\%3E3.0.CO\%3B2-Y Acesso em: 30 Set. 2017.

LIMBERG, Louise; SUNDIN, Olof, TALJA, SANNA. Three Theoretical Perspectives on Information Literacy. Human It, v. 11, n. 2, p. 93-130, 2012. Disponível http://lup.lub.lu.se/record/2798062 Acesso 23 Jun. 2017.

MACIAS-CHAPULA, C. A. O papel da informetria e da cienciometria e sua perspectiva nacional e internacional. Ciência da Informação, Brasília, v. 27, n. 2, 1998. Disponível em http://www.scielo.br/scielo.php?pid=S0100-19651998000200005\&script=sci abstract\&tIng=pt Acesso em: 30 ago. 2017.

MARTON, Ference. Phenomenography - A Research Approach to Investigating Different Understandings of Reality. Journal of Thought, v. 21, n. 3, p. 28-49, Fall 1986. Disponível em https://www.jstor.org/stable/42589189 Acesso em: 30 Ago. 2017.

MIGUEL, S.; MOYA-ANEGON, F.; HERRERO-SOLANA, V. A new approach to institutional domain analysis: Multilevel research fronts structure. Scientometrics, v. 74, n. 3, p. 331-344, 2008. Disponível em https://link.springer.com/article/10.1007/s11192-007-1586-2 Acesso em: 23 Nov. 2017.

OLIVEIRA, E. F. T.; GRÁCIO, M. C. C. Indicadores bibliométricos em Ciência da Informação: Análise dos pesquisadores mais produtivos no tema "estudos métricos" na base Scopus. Perspectivas em Ciência da Informação, Belo Horizonte, v. 16, p. 16-28, 2011. Disponível em http://www.scielo.br/scielo.php?pid=S1413-99362011000400003\&script=sci abstract Acesso em: 23 Abr. 2017.

OLIVEIRA, E. F. T.; GRÁCIO, M. C. C. Studies of Author Cocitation Analysis: A Bibliometric Approach for Domain Analysis. IRIS, v. 2, n. 1, p. 12-23, 2013. Disponível em http://www.brapci.inf.br/index.php/article/view/0000018186/e9c78c5c51142936f52d84875f0 Od4ca Acesso em: 23 jul. 2017.

SMALL, H. Co-citation in the scientific literature: a new measure of the relationship between two documents. Journal of the American Society for Information Science, v. 2, n.7, p. 28-31, 1974. Disponível em https://onlinelibrary.wiley.com/doi/abs/10.1002/asi.4630240406 Acesso 23 jul. 2017. 
SMALL, H. On the shoulders of Robert Merton: towards a normative theory of citation.

Scientometrics, v. 60, n.1, p.71-79, 2004. Disponível em https://link.springer.com/article/10.1023/B:SCIE.0000027310.68393.bc Acesso em: 23 jul. 2017.

SPINAK. E. Indicadores Cienciométricos. Ciência da Informação, Brasília, v. 27, n. 2, p. 141-148, 1998. Disponível em http://revista.ibict.br/ciinf/article/view/795/826 Acesso em: 30 abr. 2017.

SVENSSON, L. Theoretical Foundations of Phenomenography. Higher Education Research \& Development, v. 16, n. 2, p. 159-171, 1997. Disponível em https://www.tandfonline.com/doi/abs/10.1080/0729436970160204 Acesso em: 28 maio 2018.

YATES, Christine; PARTRIDGE, Helen; BRUCE, Christine. Exploring information experiences through phenomenography. Library and Information Research, v. 36, n. 112, p. 96-112, 2012. Disponível em http://www.lirgjournal.org.uk/lir/ojs/index.php/lir/article/view/496 Acesso em: 28 Maio 2018. 